\title{
PERILAKU KOMUNIKASI SUKU PEDALAMAN POLAHI DALAM BERINTERAKSI DENGAN MASYARAKAT LUAR SUKU
}

\author{
Citra Dano Putri ${ }^{1}$, Rahmat Djunaid ${ }^{2}$ \\ Fakultas Ilmu Sosial Universitas Negeri Gorontalo \\ Email:dp_citra@ung.ac.id
}

\begin{abstract}
ABSTRAK
Suku Polahi merupakan suku asli Gorontalo yang hingga saat ini masih ada dan hidup di wilayah-wilayah pedalaman Gorontalo. Salah satunya di Desa Tamaila, Kabupaten Gorontalo. Sebagai suku pedalaman, dahulu Polahi dikenal enggan untuk berinteraksi dengan masyarakat di luar suku, walaupun secara geografis tempat tinggal mereka dekat dengan perkampungan warga. Namun saat ini, khususnya di Desa Tamaila suku Polahi mulai membuka diri dan mau untuk berinteraksi dengan masyarakat desa sekitar, walaupun masih terbatas pada tujuan untuk pemenuhan kebutuhan hidup mereka. Penelitian ini bertujuan untuk melihat perilaku komunikasi suku Polahi saat berinteraksi dengan masyarakat dari luar suku mereka. Penelitian ini menggunakan metode pengumpulan data dengan cara observasi non partisipan, yang artinya peneliti hanya melihat fenomena interaksi suku polahi dan masyarakat luar suku secara umum, tanpa melibatkan diri dalam kehidupan keseharian. Hasil penelitian mengungkapkan bahwa sebagian anggota suku Polahi sudah mulai membuka diri untuk hidup berdampingan dengan masyarakat luar suku. Terbukti dari aktivitas untuk memenuhi kebutuhan hidup (mata pencaharian, dan proses jual beli di pasar). Kendala - kendala dalam berinteraksi yang ditemukan selama proses komunikasi (misalnya, kendala Bahasa dan perilaku non verbal yang mengundang perbedaan pemahaman) bisa diatasi dengan cara memanfaatkan anggota suku Polahi yang dinilai lebih berpendidikan (beberapa anak dari suku Polahi sudah bersekolah) untuk menjadi penerjemah. Peneliti menyimpulkan bahwa perilaku komunikasi suku Polahi sudah mengalami pergeseran, disebabkan adanya motivasi untuk menjalin hubungan dengan masyarakat luar.
\end{abstract}

Kata Kunci: Interaksi, komunikasi verbal, komunikasi non-verbal

\section{THE COMMUNICATION BEHAVIOR OF THE POLAHI INLAND TRIBE IN INTERACTING WITH NON-TRIBAL COMMUNITIES}

\begin{abstract}
The Polahi tribe is an indigenous tribe of Gorontalo which until now still exists and lives in the interior areas of The Polahi tribe is an indigenous tribe of Gorontalo which until now still exists and lives in the interior areas of Gorontalo. One of them is in Tamaila Village, Gorontalo District. As an inland tribe, previously the Polahi were known to be reluctant to interact with non-ethnic communities, even though geographically their place of residence was close to the residents' villages. However, at present, especially in Tamaila Village, the Polahi tribe has begun to open up and want to interact with the surrounding village community, although it is still limited to fulfilling their daily needs. This study aims to see the communication behavior of the Polahi tribe when interacting with people from outside their tribe. This study used the data collection method by means of non-participant observation, which means that the researcher only saw the phenomenon of the interaction of the Polahi ethnic group and the non-ethnic community in general, without involving themselves in everyday life. The results of the study revealed that some members of the Polahi tribe had begun to open themselves to live side by side with non-tribal communities. Evidenced by activities to meet the needs of life (livelihood, and the buying and selling process in the market). Interaction constraints encountered during the communication process (for example, language barriers and non-verbal behavior that invite differences in understanding) can be overcome by utilizing members of the Polahi tribe who are considered more educated (some children from the Polahi ethnic group are already in school) to become translators. The researcher concluded that the communication behavior of the Polahi tribe has experienced a shift, due to the motivation to establish relationships with outside communities.
\end{abstract}

Keywords: Interaction, Verbal communication, Non-verbal communication 
Korespondensi: Citra Dano Putri, S.Pd., M.I.Kom. Fakultas Ilmu Sosial Universitas Negeri Gorontalo. Wumialo, Kota Tengah, Kota Gorontalo, Gorontalo 96128.Email: dp_citra@ung.ac.id

\section{PENDAHULUAN}

Bentuk perilaku komunikasi manusia mengalami perkembangan, perubahan, dan pergeseran dari masa ke masa. Bagaimanapun perubahan/perkembangan/pergeseran ini terjadi, komunikasi tetap menjadi cara terpenting dalam menyampaikan pesan. Komunikasi juga bertujuan menjadi alat pemenuhan kebutuhan, khususnya kebutuhan sosial.

Tak ada satupun manusia yang hidup tanpa membutuhkan bantuan orang lain. Sehingga melalui komunikasi, individu bisa mendapatkan bantuan dari individu lainnya. Hal ini juga berlaku pada suku asli di sebuah wilayah. Pada beberapa daerah di Indonesia kita masih bisa menemukan suku-suku asli yang mendiami tempat-tempat terpencil, serta bersifat menutup diri dari dunia luar.

Suku Polahi adalah salah satu suku asli asal Gorontalo yang masih memilih hidup di tengah hutan dibandingkan hidup berdampingan dengan masyarakat. Walaupun aparat pemerintah desa Tamaila Utara telah membuatkan tempat untuk mereka tinggali, mereka masih memilih untuk hidup di tengah hutan. Disaat, sebagian besar masyarakat Gorontalo sudah menggunakan bahasa Gorontalo yang bercampur dengan bahasa lain (manado, dan Indonesia), suku Polahi masih tetap mempertahankan penggunaan bahasa asli Gorontalo. Hal ini mengakibatkan terjadinya hambatan komunikasi dalam hal pemenuhan kebutuhan dan mata pencaharian oleh suku Polahi sendiri.

Walaupun demikian, sudah ada beberapa masyarakat suku Polahi sendiri yang sudah bisa menggunakan bahasa Gorontalo, dan bahkan menempuh pendidikan layaknya masyarakat pada umumnya. Mereka inilah yang menjadi perantara komunikasi antara suku Polahi dan masyarakat luar suku.

Secara verbal, bahasa Gorontalo asli dan yang sudah mengalami pergeseran punya banyak perbedaan. Mulai dari susunan kata, pengucapan, hingga makna yang ditimbulkan. Adapun masyarakat suku Polahi yang sudah terbiasa berinteraksi dengan masyarakat luar suku, terdapat perbedaan dalam logat/aksen yang mereka gunakan. Yang terjadi berikutnya, suku Polahi berusaha seminimal mungkin untuk melakukan interaksi secara verbal dengan anggota masyarakat dari luar sukunya, dan lebih memilih interaksi nonverbal. Berdasarkan hasil pra-observasi yang telah dilakukan, peneliti mendapati bahwa masyarakat desa Tamaila (yang menjadi lokasi penelitian ini) mayoritas berprofesi sebagai penambang, dan mereka menggunakan jasa anggota suku Polahi untuk membantu pengangkutan barang ke lokasi penambangan (dalam istilah mereka disebut kijing).

Interaksi nonverbal juga terjadi dalam proses transaksi jual beli di pasar. Yang dimaksud dengan interaksi nonverbal disini adalah isyarat yang dilakukan, ketika mereka ingin membeli barang dari pedagang, atau justru ingin menjual hasil kebun/hewan ternak mereka. Dalam interaksinya, masyarakat suku polahi menggunakan gerak tangan (menunjuk) dalam membeli ataupun menjual bahan pokok yang mereka butuhkan. 
Secara keilmuan, penelitian ini menjadi penting dan menarik, mengingat belum banyaknya penelitian komunikasi tentang perilaku suku asli dari sebuah daerah, khususnya yang berasal dari Gorontalo.

Selain itu, penelitian ini memiliki tantangan tersendiri bagi peneliti, disebabkan sifat dan karakter dari suku Polahi sendiri, yang masih memilih hidup dan tinggal di dalam hutan. Sehingganya, peneliti memulai penelitian ini dengan pendekatan terhadap anggota suku yang dinilai secara personal telah mampu membuka diri, dan bahkan menempuh pendidikan formal seperti yang sudah peneliti sebutkan sebelumnya. Bahkan sudah ada suku polahi yang sudah menikah dengan masyarakat dan hidup di desa tamaila tersebut.

Terdapat beberapa penelitian terdahulu yang menjadi referensi peneliti. Penelitian-penelitian sebelumnya ini memiliki kesamaan konsep, dan kesamaan tema:

1. Perilaku Komunikasi Suku Bajo dalam Berinteraksi dengan Komunitas Daratan di Desa Terapung Kecamatan Mawasangka Kabupaten Buton. 2011. Yamran Sampeali Kantor Dinas Perdagangan dan Industri Kabupaten Buton.

Penelitian ini bertujuan untuk mengkaji factor-faktor yang mempengaruhi perilaku komunikasi suku Bajo dengan komunitas daratan di Desa Terapung Kecamatan Mawasangka, Kabupaten Buton, Propinsi Sulawesi Tenggara. Sampel dipilih secara purposive sebanyak 10 orang dari suku Bajo, dan 10 orang dari komunitas daratan. Metode pengumpulan data yang digunakan adalah observasi partisipatif, wawancara mendalam, dan studi dokumentasi. Data dianalisis secara deskriptif kualitatif. Hasil penelitian menunjukkan bahwa perilaku komunikasi suku bajo dengan komunitas daratan didasarkan pada adat istiadat yang masih dianut dan kebutuhan yang berkaitan dengan aktivitas mereka sebagai pelaut. Secara keseluruhan perilaku komunikasi suku Bajo didasarkan atas kuat lemahnya interaksi social dengan komunitas daratan. Faktor yang memengaruhi perilaku komunikasi suku bajo dalam berainteraksi dengan komunitas daratan, yaitu tingkat pendidikan, polapola kehidupan (system kekerabatan, pola tempat tinggal, dan pola perkawinan), bahasa, kesamaan agama, adanya kebutuhan, dan adanya bentuk-bentuk interaksi social (kerjasama, akomodasi, dan asimilasi).

2. Perilaku Komunikasi Antarbudaya Etnik Toraja dan Etnik Bugis Makassar di Kota Makassar. 2013.

Fiola Panggalo. Jurusan Ilmu Komunikasi, Fakultas Ilmu Sosial dan Ilmu Politik Universitas Hasanuddin, Makassar.

Tujuan penelitian ini adalah: (1) untuk mengetahui perilaku komunikasi antar etnik Toraja dan etnik Bugis Makassar; (2) untuk mengetahui faktor-faktor yang mendukung dan menghambat perilaku komunikasi yang terjadi antar etnik Toraja dan etnik Bugis Makassar. Penelitian ini dilaksanakan di kota Makassar. Adapun informan penelitian ini adalah orang-orang yang ditentukan secara purposive sampling yaitu dipilih berdasarkan pertimbangan tertentu bahwa mereka dianggap berkompeten untuk menjawab pertanyaan peneliti. Data primer diperoleh melalui observasi dan wawancara mendalam dengan para informan. Sedangkan data sekunder diperoleh melalui studi pustaka berupa buku-buku, jurnal dan sebagainya yang 
berkaitan dengan masalah yang diteliti. Hasil penelitian menunjukkan bahwa para pendatang dari Toraja yang tinggal di kota Makassar menggunakan bahasa Toraja sebagai bahasa kesehariannya. Meski begitu, para pendatang etnik Toraja dapat menyesuaikan bahasa yang digunakannya ketika berada ditengah-tengah masyarakat kota Makassar. Mereka sudah bisa memahami bahasa dan logat yang digunakan oleh masyarakat Makassar. Intensitas pertemuan keduanya dibeberapa tempat umum maupun tempat kerja, membuat keduanya dapat mengerti bahasa masing-masing..

\section{METODE PENELITIAN}

\section{Teknik Pengumpulan Data}

\section{Observasi}

Teknik pengumpulan observasi, adalah dimana peneliti melibatkan diri sebagai non participant observant yang melakukan pengamatan terhadap perilaku komunikasi, dan kemudian mencatatnya kedalam jurnal observasi yang disiapkan. Dalam pengamatan ini peneliti akan menggunakan jasa coder yang dipilih peneliti dari anggota suku Polahi (yang dianggap kapabel untuk membantu peneliti menerjemahkan perilaku verbal/nonverbal), maupun dari masyarakat desa Tamaila, yang dianggap cukup intens berinteraksi dengan suku Polahi.

\section{Studi Literatur}

Studi literatur disebut studi kepustakaan. Dalam penelitian ini, peneliti menggunakan teknik studi literatur baik secara online maupun offline. Peneliti datang ke perpustakaan mencari referensi buku atau catatan dan menjelajahi situs internet; akses e-book, jurnal dan skripsi yang berkaitan dengan judul penelitian ini guna melengkapi data yang ada. Selain itu, literatur yang dimaksud adalah arsip-arsip lain yang bisa diakses untuk menemukan data-data tentang suku Polahi.

\section{Dokumentasi}

Teknik dokumentasi dilakukan untuk melengkapi data yang peneliti tidak dapatkan dari proses wawancara. Dokumentasi yang dimaksud berupa foto, rekaman wawancara, maupun video yang dianggap dapat membantu peneliti menemukan data untuk penelitian ini.

\section{Teknik Analisis Data}

\section{Reduksi Data}

Jumlah data yang diperoleh dari lapangan cukup banyak, seperti catatan atau dokumen penelitian, maka dari itu perlu dicatat secara rinci dan teliti. Semakin lama peneliti di lapangan, maka akan semakin rumit pula jumlah data yang didapat. Oleh karena itu reduksi data diperlukan, peneliti merangkum, memilih dan memilah hal-hal pokoknya saja sehingga nantinya bisa terfokus pada hal-hal penting. Dalam reduksi data, nantinya peneliti akan membuat ringkasan. Peneliti mencantumkan data tersebut pada bab selanjutnya, yaitu bagian pembahasan. 


\section{Penyajian Data}

Penyajian data merupakan kegiatan ketika sekumpulan informasi tersusun sehingga memberikan kemungkinan terjadinya penarikan kesimpulan. Dalam penyajian data ini, peneliti mengumpulkan informasi beserta keterangan yang didapat di lapangan, seperti foto, bukti wawancara dengan narasumber, dan rekaman. Selanjutnya disajikan dalam bentuk kalimat naratif agar lebih mudah dibaca dan dipahami nantinya. Kemudian penyajian data akan disusun agar memiliki pola hubungan, sehingga pembaca akan lebih mudah memahami penelitian ini. Adapun dalam penyajian data, peneliti menyajikannya pada Bab IV Hasil Penelitian dan Pembahasan.

\section{Verifikasi dan Penarikan Kesimpulan}

Penarikan kesimpulan menjadi langkah terakhir. Pada langkah ini, peneliti menyimpulkan data hasil penelitian sesuai dengan masalah dan tujuan penelitian. Kesimpulan dalam penelitian ini mungkin bisa dijawab dari rumusan masalah yang sudah dirumuskan sejak awal, namun mungkin juga tidak. Kesimpulan awal yang dikemukakan hanya bersifat sementara saja, tidak menutup kemungkinan adanya perubahan jika ditemukan bukti yang kuat untuk mendukung tahap pengumpulan data berikutnya.

\section{HASIL DAN PEMBAHASAN}

Penelitian ini menemukan dalam lingkungan sosial, suku Polahi saat ini berbeda dengan zaman dahulu. Yang dimana pada zaman dahulu, polahi tersebut sangat menghindari yang kontak langsung ataupun interaksi dengan masyarakat luar suku. Seperti yang sudah dijelaskan pada pembahasan sebelumnya, mereka memilih hidup terisolir menyendiri ditengah hutan sejak zaman penjajahan Belanda. Sehingga hal itu membuat suku polahi tersebut, sama sekali tidak melakukan interaksi dengan manusia selain dari suku mereka.

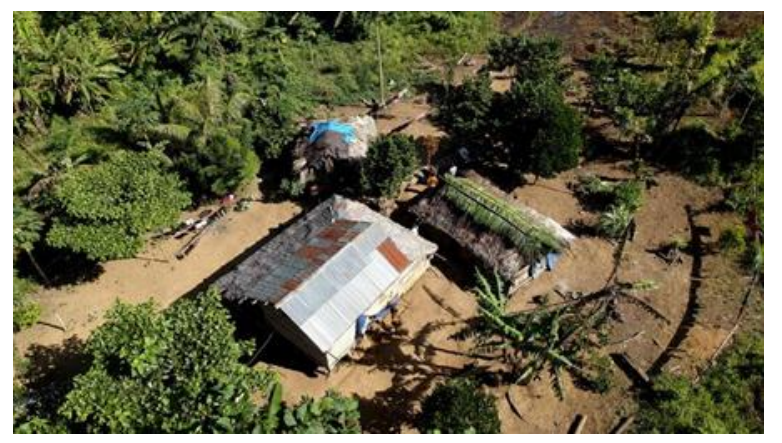

Gambar 1: Lokasi tempat tinggal suku Polahi (sumber; https://news.detik.com/foto-news/d4562257/mengenal-kehidupan-suku-pedalaman-polahi-di-gorontalo/6)

Zaman dulu pun mereka belum bisa menggunakan bahasa Gorontalo yang saat ini sering digunakan melainkan menggunakan bahasa Gorontalo zaman dulu atau masyarakat setempat menyebutnya bahasa Gorontalo asli. Saat berbicara, Polahi mengucapkan satu kata dengan tekanan kata yang lambat dengan nada yang panjang. Bahasa Gorontalo asli ini campuran dengan dialek Suwawa dan logat Boalemo. Kata-kata yang diucapkan tak mengandung huruf "R".Dalam bahasa Gorontalo asli yang mereka gunakan dulu, terdapat banyak perbedaan makna pada setiap katanya. Contohnya: Istri = Pange, Suami = Pangeya, Nikah= Pangeya, Senter $=$ Sendeli, Pedagang $=$ Dahangi, Rotan $=$ Kalanji 
Suku Polahi menggunakan bahasa Gorontalo asli dalam interaksinya, sebab dulu suku Polahi tersebut tidak mengenal bahasa Melayu ataupun Indonesia. Namun bahasa tersebut mereka gunakan pada zaman dulu, sebelum mereka membuka diri dengan dunia luar dan mulai berinteraksi dengan masyarakat. Sedangkan untuk sekarang, masyarakat suku Polahi tersebut sudah bisa menggunakan bahasa Gorontalo pada umumnya yang sering digunakan. Namun hal yang membedakan mereka dengan masyarakat di desa Tamaila tersebut, yaitu dari segi logat yang mereka gunakan. Logat yang mereka gunakan terdengar seperti logat Suwawa.

Interaksi yang terjadi antara suku Polahi dengan masyarakat, ketika adanya kepentingan antar dua pihak. Seperti dalam hal pemenuhan kebutuhan suku polahi tersebut, mulai dari bahan pokok dan juga material di pasar minggu Tamaila. Interaksi pun terjadi dalam hal pekerjaan, yang dimana beberapa masyarakat Tamaila yang berprofesi sebagai penambang memanfaatkan jasa dari Polahi tersebut untuk mengantarkan barang ke lokasi penambangan atau masyarakat sering menyebut dengan istilah "kijang".

Komunikasi Polahi saat ini sudah mengalami pergeseran, seperti yang sudah dijelaskan sebelumnya yang dimana sebagian besar mereka sudah menggunakan bahasa Gorontalo pada umumnya. Hal tersebut membuat komunikasi suku Polahi sudah tidak lagi menggunakan bahasa Isyarat dalam interaksinya dengan masyarakat desa Tamaila.

Dalam interaksi dengan masyarakat, suku Polahi tersebut hanya akan melakukan komunikasi dengan masyarakat yang punya kepentingan dengan mereka. Mereka enggan melakukan komunikasi dengan masyarakat yang tidak mempunyai kepentingan dengan mereka. Komunikasi Polahi terjadi dipasar dengan pedagang dalam hal pemenuhan kebutuhan dan juga dengan masyarakat yang menggunakan jasa mereka. Adapun masyarakat yang ingin melakukan wawancara ataupun dokumentasi terhadap mereka, harus membayar. Sebab saat ini, polahi sudah mengenal nilai tukar uang.

Persoalan tempat tinggal masyarakat suku Polahi lebih memilih tinggal ditengah hutan. Hal itu sudah terjadi secara turun temurun dari dulu. Kehidupan mereka ditengah hutan tidak menetap disuatu tempat saja, melainkan hidup secara nomaden atau berpindah-pindah. Seperti yang sudah dijelaskan dalam penjelasan sebelumnya, mereka akan meninggalkan tempat yang mereka tinggali, ketika ada salah satu dari keluarga mereka yang meninggal dan mencari tempat tinggal lain.

Kehidupan mereka yang masih memilih tinggal di tengah hutan tersebut, tidak luput dari padangan pemerintah desa. Pemerintah desa setempat telah membangunkan rumah layak huni (Mahayani) yang berdampingan dengan masyarakat di desa Tamaila Utara untuk mereka tinggali dan di biayai selama dua tahun. Tapi mereka tidak lama mendiami tempat tersebut dan saat ini, masyarakat suku Polahi kembali dan lebih memilih tinggal didalam hutan dengan alasan kondisi iklim di desa yang panas dan lahan perkebunan yang terbatas.

Walaupun demikian, hal itu bukan karena mereka masih memiliki sifat yang primitive, melainkan mereka sudah menganggap hutan sebagai tempat tinggal mereka dan perilaku mereka yang ingin bebas tanpa 
aturan. Sikap dari suku Polahi di penuhi dengan aktivitas dan perlaku yang ingin bebas ini, membuat mereka tidak tersentuh dengan etika, karena mereka hidup dengan keterasingan dengan sentuhan pendidikan, sosial dan agama, (Rahim, 2015:121-158). Adapun tradisi sosial budaya mereka menurut Madjowa antara lain: kawin sumbang/sedarah, kontak dengan pencari rotan, tidur di dekat perapian, takut kematian, setelah melahirkan langsung bekerja, berteriak di hutan, menjaga harmonisasi alam, dan bercocok tanam.

Dulu Polahi tidak mengenal pakaian seperti kaus dan celana. Mereka hanya mengenakan Pedito semacam cawat yang terbuat dari kulit kayu atau daun woka untuk menutupi kemaluan mereka. Sementara itu, bagian dada dibiarkan telanjang, termasuk para wanitanya. Namun seiring berjalannya waktu, yang dimana saat ini suku Polahi sudah membuka diri dengan dunia luar, untuk sekarang Polahi tersebut sudah mengenal yang namanya pakaian. Mereka sudah menggunakan pakaian seperti layaknya masyarakat pada umumnya. Tidak hanya mengenal pakaian, mereka juga sudah mengenal yang namanya gadget ataupun handphone.

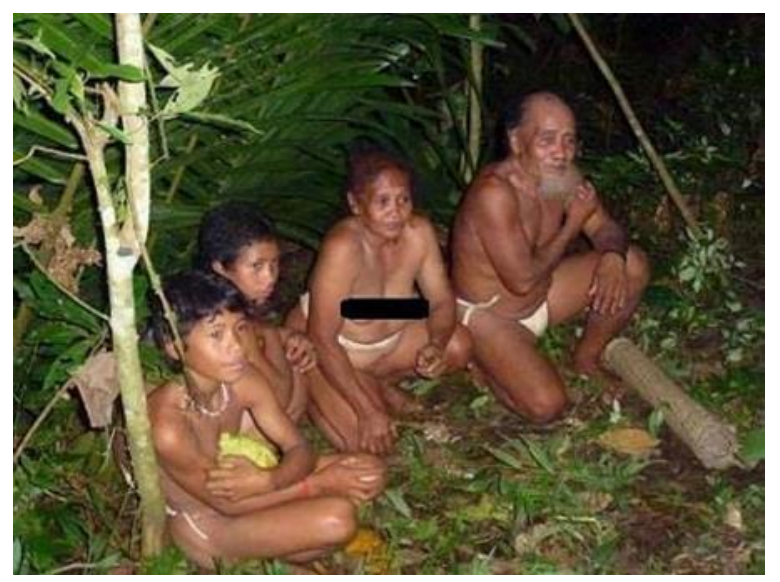

Gambar 2; tata cara berpakaian suku Polahi jaman dulu (sumber; https://news.detik.com/foto-news/d4562257/mengenal-kehidupan-suku-pedalaman-polahi-di-gorontalo/6)

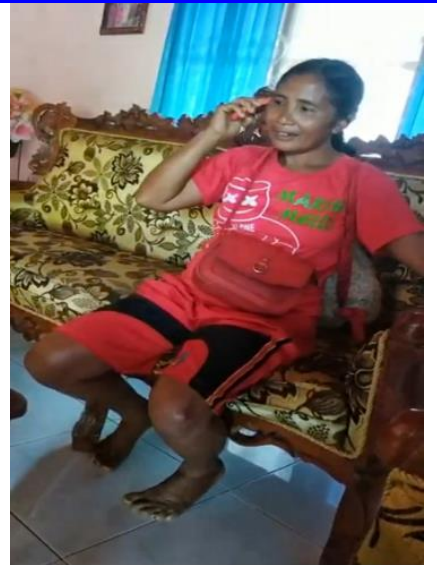

Gambar 3; salah satu anggota suku Polahi yang diwawancarai peneliti. Terlihat sudah mengenakan pakaian dan menggunakan ponsel

Layaknya kegunaan ponsel pada umumnya, Polahi juga memanfaatkan ponsel tersebut sebagai alat komunikasi berinteraksi dengan keluarga mereka yang didalam hutan dan juga masyarakat setempat. Tidak 
hanya sebagai alat komunikasi, handphone juga mereka gunakan dalam membuka video-video di jejaring sosial youtube.

Walaupun sudah mengenal teknologi, sebagian besar masyarakat suku Polahi tersebut tidak dapat membaca. Hal itu dikarenakan Polahi tidak mengenyam pendidikan sama sekali. Hanya beberapa dari anggota suku mereka yang sudah hidup berdampingan dan menikah dengan masyarakat yang sudah bisa membaca. Oleh sebab itu, dalam mengoperasikan gadget atau handphone tersebut, Polahi menggunakan dengan cara menghapal langkah-langkah dalam pengoperasian gadget atau handphone tersebut.

Seiring berjalannya waktu, lambat laun kehidupan ataupun budaya primitive Polahi zaman dulu sudah mulai di tinggalkan dan mulai mengikuti budaya yang sudah modern saat ini.

\section{SIMPULAN}

Peneliti berkesimpulan Suku Polahi saat ini bukan lah lagi suku terasing yang tidak tersentuh oleh peradaban modern. Perlahan mereka mulai membuka diri untuk menjalin hubungan dengan masyarakat dari luar suku, dan berusaha untuk beradaptasi tanpa meninggalkan nilai - nilai utama kehidupan suku mereka. Dari sisi komunikasi verbal, suku Polahi yang dahulu hanya bisa berbahasa Gorontalo asli, saat ini mulai mempelajari Bahasa Gorontalo modern. Sementara dari sisi komunikasi non-verbal, terdapat hambatan untuk menyesuaikan diri saat berinteraksi, dikarenakan kebiasaan yang sudah turun temurun. Saran peneliti adalah, pemerintah menjaga kelestarian suku ini dengan melindungi kehidupan mereka dari eksploitasi berlebihan untuk tujuan komersil.

\section{DAFTAR PUSTAKA}

Andrall. 2017. Tentang Suku Polahi yang Punya Tiga Tuhan dan Budaya Kawin Sedarah. Biar Cowok Makin Melek Sejarah!. https://www.hipwee.com/hiburan/cowok/berkenalan-dengan-suku-polahi-suku-di-pedalamangorontalo-yang-punya-budaya-meniikah-sedarah/. Diakses pada tanggal 3 Oktober 21.18

Fajar, Marhaeni. 2009. Ilmu Komunikasi: Teori dan Praktek. Yogyakarta: Graha Ilmu

Ibrahim, Arfandi. 2019. Mengenal Suku Polahi, Komunitas Adat yang Masih Langgengkan Kawin Sedarah. https://www.liputan6.com/regional/read/4048883/mengenal-suku-polahi-komunitas-adat-yang-masihlanggengkan-kawin-sedarah. Diakses pada tanggal 15 September 20.10

Laksana, W Mudibidin. 2015. Psikologi Komunikasi, Bandung: Pustaka Setia

Mulyana, Deddy. 2016. Ilmu Komunikasi: Suatu Pengantar. Bandung: Remaja Rosdakarya

Madjowa, Feriyanto dan Pomalingo, Samsi. 2015. "Kearifan Lokal Masyarakat Suku Polahi Gorontalo" Jurnal Dinamika Sosial,

Odolof, Ronny. 2013. Polahi dan Cerita Mistis yang Melingkupinya. https://regional.kompas.com/read/2013/05/07/11091556/polahi.dan.cerita.mistis.yang.melingkupinya.?page= all. Diakses pada tanggal 3 Oktober 21. 30

Patasiga, Aten. 2014. "Polahi”. Gorontalo: Universitas Negeri Gorontalo. 
Pomalingo, Samsi. 2015. Polahi : Komunitas Pedalaman Suku Gorontalo. Jurnal Dinamika Sosial Dan Budaya, Vol. 1 No.1 Juni $2015: 53-62$

Pulubuhu, Sutriyono. 2018. Kisah Masyarakat Polahi di Gorontalo yang Punya Tradisi Nikah Sedarah. https://kumparan.com/kumparannews/kisah-masyarakat-polahi-di-gorontalo-yang-punya-tradisi-nikahsedarah-1543383670778186373/full. Diakses Pada tanggal 15 September 21.20

Rahim, Sukirman."Komunitas Perilaku Lingkungan Perempuan Polahi Di Kawasan Hutan Lokasi Desa Bihe Kecamatan Asparaga Kabupaten Gorontalo", Jurnal Dinamika Sosial, Vol. 7 No.1 Juni 2015 : 121-158

Rizal. 2019. Menguak Kehidupan Suku Polahi dan Kebiasaan Pernikahan Sedarah Mereka. https://www.boombastis.com/pernikahan-suku-polahi/85205. Diakses Pada tanggal 18 September 21.10

RimbaKita, 2018. Mengenal Suku Polahi Lebih Dekat - Tradisi \& Kepercayaan. https://rimbakita.com/suku-polahi/. Diakses pada tanggal 18 September 22.18

Satriawan, Iwan. 2016. Kisah Suku Polahi dan Cerita Mistis yang Melingkupinya. https://bangka.tribunnews.com/2016/07/25/kisah-suku-polahi-dan-cerita-mistis-yangmelingkupinya?page $=2$. DIakses Pada tanggal 4 Oktober 10.10 